\title{
Die resepsie van die Nederlandse Geloofsbelydenis in Suid- Afrika, met spesifieke verwysing na die konfessionele neo- Calvinisme van die 1930's
}

\begin{abstract}
The reception of the Belgic Confession in South Africa, with special reference to the confessional neo-Calvinism of the 1930's.

This article was first read at a symposium marking the 450 year celebration of the Confessio Belgica held at the Faculty of Theology of Stellenbosch University in November 2011. It reflects on a specific aspect of the reception of the Confessio Belgica (or Nederlandse Geloofsbelydenis) in South Africa, namely the way in which the Confessio Belgica was read and interpreted by Professor E.E. van Rooyen in the 1930s. Van Rooyen, who was professor of Old Testament and Apologetics at the Theological Seminary at Stellenbosch, can be viewed as a proponent of the so-called confessional neo-Calvinism that became stronger in certain circles in the 1930s. By attending to Van Rooyen's commentary on the Confessio Belgica (as published in the journal Die Gereformeerde Vaandel between 1933 and 1937), the article identifies and underlines the way in which "Modernism" functions as a type of "enemy construction" (vyandsbeeld) in Van Rooyen's writings, over against which Reformed or Calvinist identity is posited. In light of this exploration, the final part of the article briefly reflects on the question whether the discourse in South Africa today on Reformed Confessions in general, and on the Confessio Belgica in particular, can find a way between, on the one hand, the neglect of confessional particularity and, on the other hand, insular exclusivism.
\end{abstract}

\section{INLEIDING}

Toe die personeel van die kasteel in Doornik (Tournai) vroegoggend op die 2de November 1561 ' $n$ geheimsinnige pakkie met briewe en ' $n$ geloofsbelydenis in die voorpoort gevind het, sou hulle kwalik kon raai watter verdere resepsie hierdie geloofsbelydenis in die jare en eeue daarna sou vind. Daar word algemeen aanvaar dat hierdie belydenis - wat as die Nederlandse Geloofsbelydenis (NGB) of die Confessio Belgica bekendheid verwerf het - as ' $\mathrm{n}$ gemeenskaplike belydenis van gereformeerde gelowiges in die Nederlande ontwikkel het, met die Franse predikant Guido de Bres as outeur. De Bres wou met hierdie belydenis, soos blyk uit die begeleidende brief aan Koning Filips II, asook uit die die inhoud van die belydenis, duidelik maak dat die gereformeerdes nie rewolusionêre wederdopers is nie en dat hulle verlang om volgens die suiwer evangelie van Jesus Christus te lewe.

In hierdie kort artikel wil ek nie ingaan op die lewe van De Bres of die ontstaans- en ontwikkelingsgeskiedenis van die Confessio Belgica nie. Vir die wat meer hieroor wil lees, kan ek verwys na die mooi koffietafelboek oor Guido De Bres se lewe en belydenis wat onlangs in 
Nederland gepubliseer is ${ }^{1}$, asook na Nicolaas Gootjes se boek The Belgic Confession: Its History and Sources (wat in 2007 verskyn het). ${ }^{2}$ Hierdie sake kry ook aandag in ' $n$ interdissiplinêre werk van H. L. Bosman et al wat onder die titel Die Nederlandse Geloofsbelydenis - Ontstaan, Skrifgebruik en Gebruik in 1987 verskyn³. Ek gaan ook nie 'n breë oorsig gee oor die resepsie van die NGB sedert die eerste Franse publikasies daarvan in 1561 nie. In 'n hoofstuk in die genoemde koffietafelboek oor De Bres, met as opskrif "Helder geluid klinkt ver: De Nederlandse Geloofsbelydenis van lokaal tot globaal”, word eweneens 'n nuttige oorsig oor ('n deel van) die resepsiegeskiedenis gegee, met verwysing na die neerslag van die dokument in verskillende tale en lande. Die hoofstuk meld dat daar in die 19de eeu in Suid-Afrika Nederlandse en Engelse uitgawes van die NGB verskyn het. Daar word verder verwys na die vertaling van die belydenisskrifte in Afrikaans wat in samehang met die Bybelvertaling en psalmberyming onderneem is, en in 1937 met die Psalmboek verskyn het. ${ }^{4}$ Latere kerkboeke en handboeke vir erediensgebruik sou verdere vertalingsveranderings aanbring.

Hoewel hierdie artikel nie in detail op die resepsie geskiedenis van die NGB in Suid-Afrika wil ingaan nie ('n saak wat beslis om verdere navorsing vra), wil dit wel graag aandag vra vir een vorm wat die resepsiegeskiedenis van die NGB in die 1930s in Suid-Afrika aangeneem het, met spesifieke verwysing na die skrywes van Prof E. E. van Rooyen (wat Ou Testament en Apologetiek aan die Kweekskool op Stellenbosch doseer het) in die blad Die Gereformeerde Vaandel. ${ }^{5}$

\section{KONFESSIONELE NEO-CALVINISME, DIE GEREFORMEERDE VAANDEL, EN DIE NEDERLANDSE GELOOFSBELYDENIS}

Kort na die afsluiting van die bekende Du Plessis-saak deur die Kaapse Sinode in November 1932 verskyn daar 'n nuwe teologiese blad onder die titel Die Gereformeerde Vaandel, met drie van die vier professore van die Kweekskool op Stellenbosch op die redaksie, te wete professore E.E. Van Rooyen, D.G. Malan en D. Lategan. Dié blad groei uit Die Ou Paaie, 'n blad wat weer in

1 Braekman, Émile, De Boer, Erik (reds) 2011, Guido de Bres, Zijn Leven, zijn belijden (Utrecht: Kok).

2 Gootjes, N H 2007. The Belgic Confession: Its History and Sources (Grand Rapids: Baker Academic).

3 Bosman, H L et al 1987. Die Nederlandse Geloofsbelydenis - Ontstaan, Skrifgebruik en Gebruik

(Pretoria: Universiteit van Suid-Afrika).

4 In die verband kan daar ook verwys word na " $n$ 'n artikel oor "Ons Belydenisskrifte" in die bundel Koers in die Krisis, uitgegee in 1935, waarin Ds. Daniël Erasmus melding maak van 'n ontwaking in die belangstelling ten opsigte van die kerklike belydenisskrifte, en dan noem hy dat daar verwag kan word "dat wannneer die Afrikaanse vertaling daarvan eenmaal uitgegee is, dit die ontwaakte belangstelling tot dieper ondersoek sal prikkel”. Sien Stoker, H G en Potgieter, F J M (reds), Koers in die Krisis I (Stellenbosch: Pro Ecclesia Drukkery, 1935), 103.

5 'n Mens sou natuurlik ook na ander aspekte van die resepsie van die NGB in teologiese diskoers in SuidAfrika kan verwys, soos byvoorbeeld ten opsigte van die belofte van die NGB vir kategetiese leerstof, of die manier waarop die NGB neerslag gevind in die teologiese werke van Johan Heyns en Willie Jonker. Sien in die verband: Botha, W 1972, Die Nederlandse Geloofsbelydenis as Kategetiese Leerstof (MTh tesis, Universiteit van Stellenbosch); Heyns, J A 1992, Inleiding tot die Dogmatiek aan die hand van die Nederlandse Geloofsbelydenis (Johannesburg: NG Kerkboekhandel); Jonker, W D 1994, Bevrydende waarheid: Die karakter van die gereformeerde belydenis (Wellington: Hugenote Uitgewers). Daar kan ook daarop gelet word dat Allan Boesak sy belangrike artikel "Black and Reformed: Contradiction or Challenge?" afsluit met 'n verwysing na die Nederlandse geloofsbelydenis, artikel 37: "The faithful and elect shall be crowned with glory and honour, and the Son of God will confess their names before God his Father and his elect angels; all tears shall be wiped from their eyes; and their cause, which is now condemned by many judges and magistrates as heretical and impious, will then be known to be the cause of the Son of God". Boesak, A A 1984, Black and Reformed: Apartheid, Liberation and the Calvinist Tradition (New York: Orbis), 99. 
1926 as reaksie op Du Plessis se blad Het Zoeklicht begin is. Die ontstaan van Die Gereformeerde Vaandel is moontlik gemaak deur ' $n$ groot skenking van Pieter de Waal Neethling, ' $n$ lidmaat van die gemeente Stellenbosch, wat 10000 pond ter beskikking van die trustees (Van Rooyen, Malan en Lategan) gestel het, met die doel "om ' $n$ tydskrif uit te gee ter handhawing van die suiwere leer van ons Kerk, en ter voorligting van ons volk op teologiese en godsdienstige gebied". ${ }^{6}$ Die blad het dan ook ten doel "(1) om die konfessionele standpunt van ons Kerk te handhaaf ... (2) om op hierdie hegte fondament bestendig voort te bou ... (3) om alle dwalinge te bestry". ${ }^{7}$

Dié blad kan binne die kader van die neo-Calvinistiese konfessionalisme geplaas word wat na die afloop van die Du Plessis-saak al hoe sterker na vore getree het. ${ }^{8}$ Reeds in die eerste uitgawe blyk hierdie verbintenis tot ' $n$ konfessionele (of dalk eerder konfessionalistiese) standpunt in ' $n$ artikel van Van Rooyen oor "Die Belydenis en die Handhawing daarvan deur die suiwer Gereformeerde Kerke". ${ }^{9}$ Van Rooyen verwys hierin na wat hy beskryf as die huidige ontwrigte en sorgwekkende tye en hoe dit saamhang met die naweë van die groot wêreldoorlog en die ekonomiese depressie, soveel so dat vele Westerse lande van die goudstandaard moes afstap. Maar, vervolg Van Rooyen, "wat nog veel erger en baie onheilspellender as die heersende depressie en die toenemende afstapping van die goudstandaard is, is die depressie en afstapping van die goudstandaard op die gebied van die waaragtige geloof en geestelike lewe by ons westerse volke". En die groot oorlog is vir Van Rooyen nie al rede hiervoor nie:
Die groot oorlog het dit seker ook verskerp maar reeds lank tevore het die moderne ongeloof, toenemende godsdiensverslapping en wêreldsin die Protestantse kerke van die wêreld van ons tyd binnegedring in ' $n$ verlammende depressie van die innerlike geloofslewe en afstapping van die goudstandaard van die Protestantse Belydenisse teweeg gebring. Selfs meer as een Geref. Kerk het daartoe gekom om groot offers aan die Molog van belydenisversaking te bring. ${ }^{10}$

Van Rooyen gee 'n spesifieke historiese interpretasie van die redes vir belydenisversaking en verwys in die proses na die "kille, koue Rasionalisme wat sy bevriesingsveroorsakende asem hoe langer hoe meer oor die kerklike en godsdienstige lewe van heel Europa geblaas het." ${ }^{11}$ Vir Van

6 Die Gereformeerde Vaandel, Januarie 1933: 6.

7 Die Gereformeerde Vaandel, Januarie 1933: 6.

8 Sien hieroor Vosloo, R R, "Konfessionele neo-Calvinisme na die Du Plessis-saak". NGTT 51 (Supplementum), 2010: 275-288.

9 Kritiek teen die stigting van Die Gereformeerde Vaandel sou nie uitbly nie. In Het Zoeklicht van 15 November 1932, nog voor die eerste uitgawe van Die Gereformeerde Vaandel, reageer Du Plessis krities op die skenking van Neethling en meen hy oor die blad "dat dit die reinste fundamentalisme sal verkondig" (1932:323). Hy haal verder die verklaring aan wat die trustees van die blad jaarliks moet onderteken - 'n geloofsverklaring dat die drie Formuliere van Enigheid ooreenstem met God se Woord, sowel as die verdere verwerping van, onder meer, die Ewolusie-teorie en die beskouing dat Moses nie die outeur en skrywer van die Pentateug is nie (1932:324). Na die verskyning van die eerste uitgawe van Die Gereformeerde Vaandel lewer Du Plessis weer skerp kritiek in Die Soeklig (soos Het Zoeklicht sedert 1933 heet) op die swak wetenskaplike kwaliteit van die bydraes, met spesifieke verwysing na Van Rooyen se artikel (15 Februarie 1933:35-36). Hierdie aanval van Du Plessis op Die Gereformeerde Vaandel (of soos hy dit noem, "die nuwe Neethling-blad") roep in die daaropvolgende uitgawe, soos te verwagte, weer reaksie uit. Lategan reageer namens die redaksie en meen dat Du Plessis "onsimpatiek is teenoor alles wat Gereformeerd en Kalvinisties is. Vir hom beteken dit alles Dopperisme, en elke poging om liefde in te boesem vir die Gereformeerde waarhede in ons kosbare Belydenisskrifte vervat, is slegs ' $\mathrm{n}$ verdoppering van ons Kerk" (Die Gereformeerde Vaandel, Maart 1933:94).

10 Die Gereformeerde Vaandel, Januarie 1933:12.

11 In sy analise beskou Van Rooyen veral 1816 as 'n onheilspellende jaar - die jaar toe die Nederlandse 
Rooyen is die Rasionalisme en die Franse Rewolusie hoofoorsake vir die feit dat die "kinderlike en heelhartige aanvaarding van die Heilige Skrif en die daarop gegronde Geref. Belydenis het al meer verdonker geraak" het. Die term "Modernisme" funksioneer in die konteks as 'n soort sambreelterm wat die bedreiginge vir die gesonde leer saamtrek. Hy skryf:

Ons lewe in ' $n$ tyd van hoogspanne en oormoedige modernisme in die hele beskaafte wêreld; ' $n$ modernisme wat daarop uit is om die regsinnige leer te verwater en te bestry ... Maar die Geref. Kerke moet die soet gefluit van daardie vroom getinte modernisme met moed en durf weerstaan. ${ }^{12}$

Ons sou kon sê dat die modernisme in die verband as ' $n$ tipe gereformeerde vyandsbeeld funksioneer (teenoor "regsinnigheid" of "die Calvinisme"). ${ }^{13}$ Hoe dit ook al sy, Van Rooyen stel homself ten doel om die verbintenis tot die belydenisskrifte in Die Gereformeerde Vaandel te laat neerslag vind, en tussen Maart 1933 en November 1937 verskyn daar maandeliks - op enkele uitsonderings na - artikels oor die NGB onder die opskrif "Ons Belydenisskrifte". Dié artikels word later (in 1948) in boekvorm uitgegee. ${ }^{14}$

Van Rooyen se artikels oor die NGB bied myns insiens ' $n$ belangrike venster op die neoCalvinistiese konfessionalisme van die 1930s. In 'n gesprek oor die resepsie van die NGB in SuidAfrika verdien dit dus die nodige aandag. Die deeglikheid waarmee van Rooyen sy bespreking van die NGB aanpak verdien vermelding. 'n Sekere taalgebruik val op (waarmee Du Plessis in die 1930s reeds ' $n$ mate van geïrriteerdheid mee gehad het), asook ' $n$ antitetiese houding teenoor die tydsgees. Deurgaans funksioneer die "modernisme" dus as vyandsbeeld en belydenishandhawing word as uiters noodsaaklik gesien om die nodige weerstand hierteen te bied. Ek lig hierdie gedagtes toe met enkele voorbeelde uit Van Rooyen se artikels oor die NGB.

In Maart 1933 begin Van Rooyen sy reeks oor die NGB - wat ten doel het "om in die kolomme van hierdie blad ' $n$ beskeie poging te waag om meer lig te versprei oor ons Belydenisskrifte en indien moontlik, meer liefde tot hulle weer aan te kweek". ${ }^{15}$ Die eerste afdeling handel oor die lewe van De Bres. Veral De Bres se beginselvastheid word beklemtoon, met verwysing byvoorbeeld na sy tyd in die tronk kort voor hy gehang is: "De Bres het die lyding daaraan verbonde met groot geduld en berusting verdra. Nooit het sy karakteradel met helderder glans

Hervormde Kerk die ondertekeningsformulier gewysig het. Hy wys voorts op die wysiging wat ook in Suid-Afrika aan die ondertekeningsformulier aangebring is (by die sinode van 1824), maar dat daar in 1837 weer "na die goudstandaard van Suiwer-Gereformeerde Belydenis en Belydenisondertekening teruggekeer is ... Deur so die skip van die Nederd. Geref. Kerk van die rotse van leervryheid en ongeloof weg te stuur en in die diep waters van suiwer Gereformeerde leer en belydenisondertekening sy koers weer te gee, het ons vaders die Nederd. Geref kerk "n onteenseglike groot diens bewys" (Die Gereformeerde Vaandel, Januarie 1933:17).

12 Die Gereformeerde Vaandel, Januarie 1933:17.

13 Vir ' $n$ interessante bespreking van vyandsbeelde in die gereformeerde geheue, sien die afdeling "Vijandsbeelden" in Harinck, G, Paul, H en Wallet, B (reds.), Het Gereformeerde Geheugen (Amsterdam: Uitgeverig Bert Bekker, 2009), 181-248. Naas die inleiding oor vyandsbeelde (deur George Harinck) is daar informatiewe lemmata oor "Rome" (John van Zuthem), "Franse Revolutie" (Beatrice de Graaf), "Schoolstrijd" (Roelof Bisschop), "Modernisme" (C.M. Van Driel) en "Communisme" (Wim Berkelaar).

14 Van Rooyen, E E 1948, Die Nederlandse Geloofsbelydenis (Stellenbosch: Pro Ecclesia). In Mei 1938 begin Van Rooyen met ' $n$ reeks oor die Tien Gebooie aan die hand van die Heidelbergse Kategismus. Dit word later ook in boekvorm gepubliseer. Sien Van Rooyen, E E, Die Tien Gebooie: Populêre en prakties stigtelike verklaring vaan die hand van die Heidelbergse Kategismus (Bloemfontein: Sondagskool Depot).

15 Die Gereformeerde Vaandel, Maart 1933:95. 
geskitter as in daardie aaklige gevangenis nie". ${ }^{16}$ Van Rooyen verwys na die bekende briewe wat hy uit die gevangenis geskryf het, "briewe waaruit daar onwrikbare beginselvastheid maar ook groot teerheid van hart deurstraal". ${ }^{17}$ In sy slotopmerking maak Van Rooyen 'n toepassing op die Suid-Afrikaanse konteks:

Ons lewe in ' $n$ tyd van toenemende beginselloosheid en papheid op godsdienstige en sedelike gebied ... ook in Suid-Afrika ... By baie mense is die yster uit die bloed en die staal uit hulle wil weg ... Mag dit God die Heer behaag om ooit in Suid-Afrika in hierdie ontwrigte tye, weer manne van die stempel van de Bres te vorm en in sy diens te gebruik. ${ }^{18}$

In April 1933 vervolg Van Rooyen sy reeks en gee hy ' $n$ bondige oorsig oor die NGB, asook ' $n$ nadere uiteensetting van Artikel 1. In die daaropvolgende maande bespreek Van Rooyen die NGB artikel vir artikel. ' $n$ Sekere teologiese stellingname blyk duidelik en dit word veral weerspieël in Van Rooyen se slotopmerkings by elke artikel. Deurgaans word die gevaar van dwaling beklemtoon. Sy slotopmerking by die bespreking van artikel 12 (oor die skepping van alle dinge) is tekenend van hierdie aksent.

Dwalinge was daar altyd en sal daar steeds in 'n wêreld van sonde wees. Sulke dwalinge moet deur die kerk steeds by die lig van die Heilige Skirf ondersoek en blootgelê word. En dan moet hulle, hoe skoonskynend hulle ook al mag wees, "vewerp en verfoei" en nie vertroetel word nie. So alleen kan die Kerk en die enkele Christenmens geestelike sterk en veerkragtig word en bly. Anders bly die dwaling op die kerklike lewe soos ' $n$ bloedsuier sit, en verteer die kragte van die Kerk en Christendom gaandeweg. ${ }^{19}$

Deurgaans vorm, soos genoem, die Modernisme 'n tipe vyandsbeeld. As slotopmerking by die bespreking van Artikel 9 oor die Drie-eenheid skryf Van Rooyen byvoorbeeld: "Die Modernisme in sy konsekwente vorm loën hierdie waarheid op 'n plompe wyse; en waar dit die oorhand in die kerk kry word dit die dood in die pot vir so 'n kerk. Omdat die modernistiese loëning van die Drie-eenheid so ' $n$ kerkgemeenskap in sy hartaar aantas. Wees op u hoede, geagte leser, vir die soet maar verraderlike gefluit van die Drie-eenheidsloëning van die modernisme." ${ }^{20}$ En in die bespreking van artikel 29 oor die ware kerk, het hy dit soos volg oor die kerkvervalsing in Protestantse geledere:

Dit is die kerke waarin die holle, heillose modernisme vaste voet en die oorhand gekry het. In daardie Kerke is die vervalsing nog erger as in die Roomse Kerk. Immers die Woord van God word eenvoudig weggekritiseer; aan die hoogheilige Persoon van Christus sy godheid ontsê, sy soendood weggedoesel, en die twee sakramente van alle ware betekenis ontdoen.

16 Die Gereformeerde Vaandel, Maart 1933:94.

17 Die Gereformeerde Vaandel, Maart 1933:94.

18 Die Gereformeerde Vaandel, Maart 1933,:97

19 Die Gereformeerde Vaandel, Junie 1934:173. Hierdie aksent kom telkens voor. In die bespreking van artikel 3 skryf Van Rooyen byvoorbeeld: "Nie die kortsigtige en dwaalsieke mens moet die Heilige Skrif kritiseer nie - maar die Skrif moet die mens kritiseer". En as slotopmerking by artikel 7, oor die volkomenheid van die Skrif, lees ons: "Die skuldige en blywende plig van elke ernstige Belyer is om die oppervlakkige en verderflike leringe van daardie geeste, of dwaalsieke mense steeds op die proef te stel: die leringe aan die hand van die Heilige Skrif te ondersoek en te toets, en as dit daarmee stry, dit dan van gansche harte te verwerp ... So alleen sal hy bestand wees en bly teen die suigkrag van die tydsgees met al sy ongeloof, bygeloof, wêreldsin en akelige ongeregtigheid" (Desember 1933: 415).

20 Die Gereformeerde Vaandel, Februarie 1934:50. 
Verskillende Kerke is reeds diep deur hierdie kwaad aangetas. Mag ons Ned. Geref. Kerk daarvoor bewaar bly. ${ }^{21}$

Deurgaans pleit Van Rooyen in sy bespreking dat die gelowiges nie moet slap wees te midde van die bedreiginge van die tyd nie. Die slotopmerking in die bespreking van die artikel oor die uitverkiesing is verteenwoordigend van hierdie aksent:

Dit is ' $n$ tyd van groot oppervlakkigheid, waarin selfs baie christene as slappe riete deur allerlei winde van vreemde leer heen en weer gebuig word. Die gelowige en kinderlike aanvaarding van die uitverkiesingsleer, soos hierbo omskrywe, sal hulle lewensbootjie die regte koers deur die deindende bare en golwe laat hou." 22

Die gereformeerde gelowige moet daarom "vashou" aan die belydenis om die onstuimige tydsgewrig te kan weerstaan. ${ }^{23}$

Om saam te vat: Van Rooyen gee 'n deeglike bespreking van die NGB, maar duidelik sien hy die tydsgewrig as onheilspellend, onstuimig, benard, oppervlakkig en sorgwekkend. Deurentyd is daar sprake van die gevaar van verslapping in die lig van die bedreiging van die modernisme en ander "ismes" (soos Rasionalisme en Kommunisme). Gereformeerdes moet hulle identiteit

21 Die Gereformeerde Vaandel, Junie 1936:173. Soortgelyke gedagtes kom dikwels voor. In die slotopmerking by die bespreking van Artikel 10 oor die godheid van Christus skryf Van Rooyen: "ons leef in " $n$ tyd van toenemende afval en ongeloof ... Veral ook die leerstuk van die waaragtige Godheid van Christus word in die kringe van die ongelowige wysbegeerte en van die leë en luidrugtige modernisme op kerklike gebied aangeval, soms deur plompe loëning en dan weer deur listige verwatering daarvan" (April 1934:105). En in die artikel oor die nagmaal (artikel 35): "Dog die houding van besliste afwysing moet nie alleen teenoor Roomse misbruike ingeneem word nie. Dit moet stellig ook aan die dag gelê word met betrekking tot die slappe Nagmaalsopvatting van rasionaliste en moderniste in die geledere van die Protestantse kerk" (Augustus 1937, 239). In die bespreking van Artikel 36 word die bedreiging van die Kommunisme by die van die Rasionalisme en die Modernisme gevoeg: "Ons lewe tans in " $n$ tydsgewrig waarin die Kommunisme op nog baie erger en onheilspellender wyse die kop uitsteek. Die voorstanders van die Kommunisme van die sestiende eeuse Wederdopers het nog by hulle oproerigheid die geloof aan God vasgehou. Die hedendaagse Kommunisme wortel egter in 'n stryd-lustige ateïsme of godloënary" (September 1937:269).

22 Die Gereformeerde Vaandel, Oktober 1934:309. Op dieselfde bladsy as hierdie artikel verskyn daar ook " $n$ insetsel oor "Die Modernisme" wat onder meer na die "verderwende, afbrekende werk" van die Modernisme verwys. Dieselfde uitgawe bevat " $n$ artikel wat skerp afwysend is op Du Plessis se kritiek op die Vrystaatse kerk se verandering van die formulier vir die indiensneming van predikante (310-312).

23 Van Rooyen skryf byvoorbeeld na aanleiding van artikel 26 oor die middelaarskap van Christus: "Die Roomse kerk misken Christus se middelaarskap van voorbidding. Maar ons lewe in " $n$ tydgewrig waarin ook die Protestantse wêreld vele mense met die middelaarswerk van Christus in alle opsigte eenvoudig skoonskip maak. Unitariërs en allerlei slag van ander moderniste doen dit onomwonde. Sowel teenoor hulle loëning as teenoor die Roomse miskenning moet ons as Gereformeerdes 'vashou' aan die volle middelaarskap van Christus. Daarin lê die krag tot lewe en tot weerstand" (Januarie 1936:18). Na aanleiding van artikel 28 oor die ware kerk klink "n soortgelyke gedagte: "Teenoor daardie ongelowige en eiegeregtige tydsgees moet die ware gereformeerde steeds stel ' $n$ hartgrondige aanvaarding en kloeke belydenis van al die waarhede van die Christelike godsdiens. Só alleen sal hy instaat wees om die tydsgees die hoof te bied" (Maart 1936:90). En in die bespreking van artikel 32 oor die tug, skryf Van Rooyen in dieselfde trant: "Ons lewe in "n by uitstek losbandige en tugtelose tydsgewrig ... Mag die Here God aan alle ampsdraers in ons Kerk en ook ander Kerke veel krag en moed gee om steeds onbevreesd die snoeimes van gesonde tugoefening te hanteer en alle skadelike en krag-opswelgende waterlote uit die wingerd van ons kerklike lewe uit te knip" (Januarie 1937:20). 
beskerm en selfs versigtig wees vir samewerking met ander kerke en liggame. ${ }^{24}$ Van Rooyen se slotopmerking in die laaste artikel van die reeks oor die NGB trek ' $n$ hele aantal grondmotiewe saam:

Wat ons benarde tyd broodnodig het, is ' $\mathrm{n}$ ruim aantal mannen en vroue, 'standvastig, onbeweeglik, sterk' in die geloof en wel 'n geloof met ' $n$ positief-Christelike inhoud, soos die Geloofsbelydenis tot ons spreek. Dan sal ons gewisselik nie soos slappe riete deur 'allerlei winde van onsuiwere leer' heen en weer gebuig word nie, of deur die soetgefluit en oppervlakkige gekeuwel van die hedendaagse sektewese van koers gebring word nie. Met so 'n geloof sal ons dan "rustig te midde van die golwe' kan bly. ${ }^{25}$

\section{DIE NEDERLANDSE GELOOFSBELYDENIS VANDAG: ANDERKANT INTROVERTE GESLOTENHEID EN STRYDVAARDIGE EKSKLUSIWITEIT?}

Van Rooyen se skrywes oor die NGB moet in die konteks van sy tyd beoordeel word. Nogtans kan genoem word dat dit duidelike trekke van die konfessionele neo-Calvinisme van die 1930s en daarna vertoon. Dit is verder moeilik om nie die nawerking van die Du Plessis-saak in talle van Van Rooyen se opmerkings oor die toepassing van die belydenis in te lees nie (Van Rooyen was, soos genoem, 'n sterk teenstanders van Du Plessis). Ek dink Hennie Rossouw vat dit goed saam in 'n insiggewende praatjie oor "Die Du Plessis-saak" (gelewer by 'n byeenkoms van die Degenaarbesprekingsgroep op 2 Desember 2000 te Stellenbosch), wanneer hy die opmerking maak dat na die Du Plessis-saak "die gees ... van gekontroleerde intellektuele openheid teenoor buite-kerklike denke, en van akkommodering van verskillende binne-kerklike vertolkings, dit met verloop van tyd verloor het teen ' $n$ meer doktrinêre, verabsoluterende en antitetiese gees van introverte geslotenheid en strydvaardige eksklusiwiteit". ${ }^{26}$ In so "n konteks funksioneer die verstaan van die belydenisskrifte dan maklik in diens van ' $n$ "introverte geslotenheid" en " $n$ "strydvaardige

24 Van Rooyen is ook skeptiese teenoor samewerking met ander organisasies (elders in Die Gereformeerde Vaandel skryf hy skerp krities teen die CSV, en in die laatdertiger jare sou Die Gereformeerde Vaandel ' $n$ kritiese houding inneem teenoor B. B. Keet se verstaan van die ekumene en die eenheid van die kerk). In die bespreking van die artikel oor die doop skryf Van Rooyen: "Ons lewe in 'n tydsgewrig waarin daar op kerklike gebied die groot en klinkende woord van saamwerk, saamstaan almeer verneem word. Daar word vroeg en laat aangedring op samewerking met met allerlei s.g. christelike liggame en strominge, maar waarvan die eg Protesantse karakter byna geheel en al verbleek het, ook op die punt van die instelling van die doop en sy betekenis ... Daarom moet ons die gehoor gee aan die geroep om samewerking met genoemde liggame en strominge baie versigtig wees, en steeds skerp toesien dat ons gereformeerde, gesond-skriftuurlike geloofs-standpunt nie verwater word of geweld aangedoen word nie" (139).

25 Die Gereformeerde Vaandel, November 1937:337.

26 Rossouw, H W, "Die Du Plessis-saak", 14. In hierdie (na my wete ongepubliseerde) praatjie wys Rossouw daarop dat daar ook in die politieke lewe in dieselfde dertigerjare met die opkomende Afrikaner volksbewussyn 'n nuwe oriëntering en klem gekom het. In die lig van hierdie hierdie verskuiwings op kerklike, teologiese en politieke gebied merk Rossouw teen die einde van sy praatjie op: "Die ontdekkende gees van grensoorskryding en inklusiwiteit, van uitreikende kommunikasie en kontak met die vreemde, van die uitskuif van horisonne en die ontgin van nuwe perspektiewe het, so lyk dit my, in die dertigerjare dus op meer as een terrein van die Afrikanerkultuur in die slag gebly" (15). Sien ook Kinghorn se opmerking dat die hantering van die Du Plessis-saak in die Ned. Geref. Kerk tot die ontstaan van ' $n$ hermeneutiese vakuum aanleiding gegee het: "Ná die Du Plessis-saak was daar geen klimaat meer vir ' $n$ sinvolle en kritiese ondersoek en debat oor sake van disputeerbare aard nie. Vir jare daarna sou agterdog heers oor enige poging om die hermeneutiese vraag voluit ernstig te behandel". Sien ook Kinghorn, J (red), Die NG Kerk en Apartheid (Johannesburg: MacMillan, 1986), 55-56. 
eksklusiwiteit". In die gereformeerde kerke wat met wit Afrikaanssprekendes geassosieer word, het hierdie grondhouding dikwels met 'n onkritiese omhelsing van die opkomende Afrikaner nasionalisme en patriotisme saamgehang. In die nadenke oor die betekenis van die belydenskrifte vir vandag, moet hierdie spesifieke resepsiegeskiedenis - en die impak daarvan

op die teologiegeskiedenis - myns insiens deeglik verreken word.

Ek sluit af met drie kort opmerkings na aanleiding van bogenoemde bespreking:

- Met die onlangse besluite van die Ned. Geref. Kerk oor die aanvaarding van die Belhar belydenis is die gesprek oor die belydenis van die kerk opnuut in die brandpunt. Dikwels word die pleidooi gehoor dat die gesprek oor Belhar saam met 'n gesprek oor die aard van gereformeerde belydenisskrifte, asook met ' $\mathrm{n}$ bestudering van die drie formuliere van eenheid, moet geskied. Dit is inderdaad ' $n$ belangrike aksent. In die proses is dit wel belangrik dat daar gewaak moet word teen 'n oorspanne konfessionaliteit, soos wat ek meen dit in sekere gereformeerde kringe in die 1930s en daarna neerslag gevind het. Vandag lê ons uitdagings sekerlik anders, maar dit bly steeds noodsaaklik om 'n verantwoordelike weg te vind tussen - aan die een kant - konfessionalistiese engheid waarin die belydenisskrifte as ' $n$ tipe sjibbolet vir teologiese (en politieke) konserwatisme funksioneer, én - aan die ander kant - 'n houding van konfessionele ongeërgdheid waarin die belydenisskrifte bloot antikwariese waarde het en geen wesenlike rol in die lewe van die kerk en die teologie speel nie.

- 'n Tweede opmerking: Met die lees van Van Rooyen se kommentaar op die NGB val die fokus op die gevaar van dwaling op, asook dat die belydenisskrifte help om dit te bestry. Hierdie fokus is uiteraard belangrik in die gesprek oor die belydenisskrifte. Maar dit is beslis ' $n$ verskraling as die belydenisskrifte meestal gebruik word as "'n stok om mee te slaan" en nie as " $n$ "staf of mee te gaan nie" of as " $n$ "lied" nie. Die belydenisskrifte moet as spreekreël vir die prediking dien en ook die gemeente tot lofsang aanspoor. ${ }^{27}$ Hiervoor is nie net herhaling van die tradisie nodig nie, maar ook wat mens ' $n$ "tradisiegeïnformeerde kreatiwiteit" kan noem. Dit gaan oor die verbintenis aan die tradisie as 'n lewende tradisie. ${ }^{28}$

- Ten slotte: Eweneens moet daar 'n weg tussen geslote identiteitsdenke en identiteitsontkenning gesoek word. Hierdie weg dui in die rigting van identiteitsverruiming. Daar is die verleiding om die belydenisskrifte so te gebruik dat dit in diens van 'n eng identiteitsdenke staan. Die belydenisskrifte word dan gebruik om skerp grense tussen regsinniges en liberales (of watter etikette ook al gebruik word) te trek. In ' $n$ tydsgees wat as bedreigend beleef word, word oorlewing op kerklike en teologiese gebied dan met ' $n$ streng handhawing van die belydenisskrifte gelykgestel en word in die proses geen plek vir ' $n$ kritiese hermeneutiek, 'n historiese bewussyn of 'n ekumeniese openheid gelaat nie. Die taal van oorlewing kan juis ' $n$ weerspieëling van geslote identiteitsdenke wees en as motivering daarvoor dien. Hierteenoor moet onthou word dat Christelike kerke nie in die eerste plek geroep is om te oorleef nie, maar om in die lig van die bevrydende waarheid van die evangelie as versoende gemeenskappe te oorleef in geregtigheid. Dit beklemtoon, myns insiens, waarom die gesprek oor die teologiese

27 Vgl. Jonker, Bevrydende waarheid, 9, in aansluiting by Van Ruler en Noordmans.

28 Vir " $n$ bespreking wat die begrip "lewende tradisie" in gesprek bring met die Gereformeerde tradisie in Suid-Afrika, sien my artikel "Reforming Tradition? Remarks on Reformed Theology in South Africa, in Conversation with Alasdair MacIntyre". Journal of Theology for Southern Africa 139:18-31. 
betekenis van die NGB in Suid-Afrika vandag nie van die gesprek oor die toe-eiening van die Belhar belydenis losgemaak kan word nie.

\section{KEY WORDS}

The Belgic Confession

Neo-Calvinism

Die Gereformeerde Vaandel

EE van Rooyen

Modernism

Reception History

\section{TREFWOORDE}

Die Nederlandse Geloofsbelydenis

Neo-Calvinisme

Die Gereformeerde Vaandel

EE van Rooyen

Modernisme

Resepsie-geskiedenis

Kontakbesonderhede:

Prof RR Vosloo

Fakulteit Teologie

Privaatsak X1

7602 MATIELAND

Kant; 0218083256

Huis:021 8800604

Sel: 0723413806

E-pos: rrvosloo@sun.ac.za 